\title{
The Association Between Objectively Measured Physical Activity and Academic Achievement in Dutch Adolescents: Findings From the GOALS Study
}

Citation for published version (APA):

Van Dijk, M. L., de Groot, R. H., Savelberg, H. H., van Acker, F., \& Kirschner, P. A. (2014). The Association Between Objectively Measured Physical Activity and Academic Achievement in Dutch Adolescents: Findings From the GOALS Study. Journal of Sport \& Exercise Psychology, 36(5), $460-473$. https://doi.org/10.1123/jsep.2014-0014

Document status and date:

Published: 01/01/2014

DOI:

10.1123/jsep.2014-0014

Document Version:

Publisher's PDF, also known as Version of record

Document license:

Taverne

Please check the document version of this publication:

- A submitted manuscript is the version of the article upon submission and before peer-review. There can be important differences between the submitted version and the official published version of record.

People interested in the research are advised to contact the author for the final version of the publication, or visit the DOI to the publisher's website.

- The final author version and the galley proof are versions of the publication after peer review.

- The final published version features the final layout of the paper including the volume, issue and page numbers.

Link to publication

\footnotetext{
General rights rights.

- You may freely distribute the URL identifying the publication in the public portal. please follow below link for the End User Agreement:

www.umlib.nl/taverne-license

Take down policy

If you believe that this document breaches copyright please contact us at:

repository@maastrichtuniversity.nl

providing details and we will investigate your claim.
}

Copyright and moral rights for the publications made accessible in the public portal are retained by the authors and/or other copyright owners and it is a condition of accessing publications that users recognise and abide by the legal requirements associated with these

- Users may download and print one copy of any publication from the public portal for the purpose of private study or research.

- You may not further distribute the material or use it for any profit-making activity or commercial gain

If the publication is distributed under the terms of Article $25 \mathrm{fa}$ of the Dutch Copyright Act, indicated by the "Taverne" license above, 


\title{
The Association Between Objectively Measured Physical Activity and Academic Achievement in Dutch Adolescents: Findings From the GOALS Study
}

\author{
Martin L. Van Dijk, ${ }^{1}$ Renate H.M. De Groot, ${ }^{1}$ Hans H.C.M. Savelberg, ${ }^{2}$ \\ Frederik Van Acker, ${ }^{1}$ and Paul A. Kirschner ${ }^{1}$ \\ ${ }^{1}$ Open University of the Netherlands; ${ }^{2}$ Maastricht University
}

\begin{abstract}
The main goal of this study was to investigate the association between objectively measured physical activity and academic achievement in adolescents. Students in Grades 7 and $9(N=255)$ were included. Overall, we found no significant dose-response association between physical activity and academic achievement. However, in Grade 7 total physical activity volume (Total PA) was negatively associated with academic achievement, while moderate-to-vigorous physical activity (MVPA) was negatively associated with both academic achievement and mathematics performance. In contrast, in Grade 9 both Total PA and MVPA were positively associated with mathematics performance. In addition, the overall association between MVPA and academic achievement followed an inverted U-shaped curve. Finally, Total PA was positively associated with executive functioning, while executive functioning in turn mediated the associations between Total PA and both academic achievement and mathematics performance. These results indicate that the association between physical activity and academic achievement in adolescents is complex and might be affected by academic year, physical activity volume and intensity, and school grade.
\end{abstract}

Keywords: exercise, accelerometry, school performance, youth

Physical activity generates positive structural changes in the brain, such as neurogenesis, angiogenesis, and improved connectivity (Thomas, Dennis, Bandettini, \& Johansen-Berg, 2012). These positive effects of physical activity on the brain may consequently improve academic achievement. Many studies have indicated that children who spend more time in physical activities have better academic achievement than those who are less physically active (Fedewa \& Ahn, 2011). Most of these studies have focused on young children $(<12$ years old), while adolescents (12-18 years old) as a group has received less attention. Results from children are difficult to generalize to adolescents because of the multiple physiological, emotional, and behavioral changes that occur during the adolescent period (Crone \& Dahl, 2012). For example, the frontal brain lobes develop rapidly through myelination and synaptic pruning during the adolescent years (Steinberg, 2005). It is known that the frontal

Martin L. Van Dijk, Renate H.M. De Groot, Frederik Van Acker, and Paul A. Kirschner are with the Welten Institute, Faculty of Psychology and Educational Sciences, Open University of the Netherlands, Heerlen, The Netherlands. Hans H.C.M. Savelberg is with the Department of Human Movement Sciences, Maastricht University, Maastricht, The Netherlands. Address author correspondence to Martin L. Van Dijk at martin.vandijk@ ou.nl. brain lobes are involved in the regulation of executive functions, which are of crucial importance to success in school (Crone \& Dahl, 2012) and are positively correlated with mathematics performance (Bull \& Scerif, 2001). Because physical activity has been found to have positive effects particularly on the frontal brain lobes (Guiney \& Machado, 2013), the adolescent period is an interesting period to investigate the association between physical activity and (frontal lobe) brain functioning and consequently academic achievement.

Most studies on the associations between physical activity and academic achievement in adolescents have used questionnaires (i.e., self-report) to measure physical activity (Coe, Pivarnik, Womack, Reeves, \& Malina, 2006; Daley \& Ryan, 2000; Fox, Barr-Anderson, Neumark-Sztainer, \& Wall, 2010; Sigfúsdóttir, Kristjánsson, \& Allegrante, 2007; So, 2012; Tremblay, Inman, $\&$ Willms, 2000). This subjective measure of physical activity has several limitations, such as social desirability, recall bias (Slootmaker, Schuit, Chinapaw, Seidell, \& van Mechelen, 2009), overestimation of time spent in moderate-to-vigorous physical activity (Chinapaw, Slootmaker, Schuit, van Zuidam, \& van Mechelen, 2009), and underestimation of time spent in light physical activity (Bassett, Cureton, \& Ainsworth, 2000). The latter, underestimation of time spent in light physical activity, 
is an important limitation for researchers investigating associations between physical activity and academic achievement. First, time spent in light physical activities accounts for a high proportion of the variability in total physical activity volume (McCrorie, Duncan, Granat, \& Stansfield, 2012). Second, light physical activity is positively associated with physical health in adolescents (McCrorie et al., 2012) and thus might be positively associated with academic achievement as well (Ickovics et al., 2014).

Positive associations between self-reported physical activity and academic achievement in adolescents have been found in the majority of studies (Coe et al., 2006; Fox et al., 2010; Sigfúsdóttir et al., 2007; So, 2012). In contrast, no association was found between physical activity and academic achievement in English adolescents (Daley \& Ryan, 2000). In addition, Tremblay et al. (2000) identified a weak but negative association between physical activity and academic achievement in 12-year-old Canadian adolescents. The authors suggested that physical activity might, up to some optimal level, be positively associated with academic achievement, while too much time spent on physical activity might detract from academic pursuits, resulting in a poorer academic achievement. The study of Syväoja et al. (2013) supports this conclusion; an inverse U-shaped curvilinear association was found between self-reported moderateto-vigorous physical activity and academic achievement in Finnish early adolescents.

To our knowledge, only three studies have investigated the associations between objectively measured physical activity and academic achievement in adolescents, and they reported mixed results. Kwak et al. (2009) found a positive association between vigorous physical activity and academic achievement in Swedish adolescent girls, but no significant association in boys. In contrast, Syväoja et al. (2013) reported no significant association between moderate-to-vigorous physical activity and academic achievement in Finnish early adolescents. Finally, Booth et al. (2014) determined that total physical activity volume was negatively associated with academic achievement in unadjusted models. In contrast, moderateto-vigorous physical activity, as a percentage of the total physical activity volume, was positively associated with academic achievement in English adolescents. A limitation of these studies was that the accelerometers they used were placed on the participants' hip, which limits the ability to capture nonambulant activities, such as cycling (Chillon et al., 2011). In addition, differences in adolescents' physical activity levels between weekdays and weekend days (Jago, Anderson, Baranowski, \& Watson, 2005) were not taken into account.

The main goal of this study was to investigate the association between objectively measured physical activity and academic achievement in Dutch adolescents in Grades 7 and 9. In addition, we investigated whether this association was moderated by sex and academic year. Finally, we explored whether the association between physical activity and academic achievement was medi- ated by executive functioning. We measured habitual physical activity levels with an ActivPAL3 accelerometer placed on the thigh and account for differences between weekdays and weekend days. We used two measures of physical activity: total physical activity volume per week (Total PA) and total moderate-to-vigorous physical activity per week (MVPA). Results were controlled for several covariates related to physical activity and academic achievement, such as sex, nationality, socioeconomic status (SES), body mass index (BMI), cardiovascular fitness, depressive symptoms, and self-esteem (Castelli, Hillman, Buck, \& Erwin, 2007; Kwak et al., 2009; Sigfúsdóttir et al., 2007). We hypothesized a positive dose-response association between physical activity and academic achievement in adolescents, in line with research of Booth et al. (2014) and Kwak et al. (2009). In addition, we explored whether the association between physical activity and academic achievement followed an inverted U-shaped curve based on research of Syväoja et al. (2013).

We investigated several factors, such as sex, academic year, and executive functioning, which might influence the association between physical activity and academic achievement in adolescents. First, we explored interaction effects between physical activity and sex on academic achievement and hypothesized that the association was more positive in girls than in boys, in line with Kwak et al. (2009). Second, the transition from elementary school to secondary school (Grade 7 is the first year of secondary school in the Netherlands) might result in more negative thoughts about school and lower academic motivation (Wigfield, Eccles, Iver, Reuman, \& Midgley, 1991). Because of the transition from elementary to secondary school in Grade 7 students, we hypothesized that the association between physical activity and academic achievement was weaker in Grade 7 compared with Grade 9. Third, a study of Booth et al. (2013) showed that physical activity might benefit key components of executive functioning in adolescents, while executive functioning in turn has been found to be importantly related with academic achievement (Crone \& Dahl, 2012). Therefore, we investigated whether the association between physical activity and academic achievement was mediated by executive functioning and explored interaction effects of sex and academic year.

\section{Methods}

\section{Study Sample}

The data source was The GOALS (Grootschalig Onderzoek naar Activiteiten van Limburgse Scholieren [Largescale Research of Activities in Dutch Students]) Study. This cross-sectional study was conducted at a secondary school in the south of the Netherlands. Data collection took place during normal school weeks from October 2011 to March 2012. The study was approved by the local Ethical Committee of the Open University of the Netherlands. 
All students in Grade 7 and Grade 9 of senior general secondary education or university preparatory education level were invited to participate $(N=526)$. A sample of 440 Dutch-speaking adolescents was willing to participate $(83.7 \%)$. To increase the homogeneity of the study sample, students who had either skipped or repeated a year were excluded (73). In addition, 24 students were excluded from our analyses because of health or concentration problems (8), illness or injuries throughout the entire week (8) or measurement failures of the accelerometer during the data collection week (8). In addition, 88 participants did not wear the accelerometer for at least four valid days, including both weekend days, and were, therefore, excluded. As a result, 255 participants were included in analyses.

\section{Procedures}

Before starting the study, information about the background, goals, and procedures of the study was distributed to students of the selected classes. An invitation to an informative presentation about the study was attached for the parents and/or guardians. Parents and/or guardians signed an objection form in case they did not agree with participation of their children or in case the students themselves did not agree to take part in the study. Whenever possible, data were collected by the same research assistants who had been trained with standard protocols and were given standardized instructions to use.

Accelerometers were taped on the midpoint of the anterior part of the right thigh of the participants using a Tegaderm (3M, St. Paul, MN, US) transparent film roll. Participants were asked to wear the device continuously for one full week, $24 \mathrm{hr} /$ day. To increase compliance, participants were allowed to shift the device to the left thigh if it irritated their skin. (Before our study, a pilot study employing 23 students wearing an ActivPAL 3 accelerometer for one complete day on both legs reported an almost perfect Pearson correlation $(r=.997, p<.001)$ in the number of accelerometer steps between the left and right thigh.) After attaching the accelerometers, participants took a 20-m shuttle-run test and then completed several questionnaires. They were also asked to keep a diary during the full week in which they reported vigorousintensity physical activities, the times they went to bed and awoke, and any other relevant details such as problems with the accelerometer, illness, or injuries. Exactly 1 week later, participants returned their accelerometers and diaries. After finishing the study, participants received a gift voucher of 15 euros for their full participation. At the end of the academic year, school grades for Dutch, mathematics and English throughout the entire academic year were provided by the school.

\section{Measures}

Physical Activity. The ActivPAL3 accelerometer (Paltechnologies, Glasgow, UK) was selected to measure habitual physical activity levels during a normal school week. This small device $(53 \times 35 \times 7 \mathrm{~mm})$ measures bodily accelerations and identifies the wearer's posture. Data were recorded at $20 \mathrm{~Hz}$ and summarized in 15-s time intervals (epochs). Data output for each epoch included number of steps, energy expenditure (metabolic equivalent per hour), and time spent sitting/lying, standing, and moving.

Data were downloaded and processed with ActivPAL Professional software (version 6.4.1). A valid day was considered to be a day that the student wore the accelerometer for the whole day (i.e., $24 \mathrm{hr}$ of wear time). Atypical schooldays (i.e., weekdays without school lessons) and days when the student reported sickness or injury in his/her diary were excluded. Because the accelerometer was taped at the thigh of the students, nonwear time was not an issue. Nevertheless, we used the weekly overviews of the accelerometer data to determine whether the students removed the accelerometer during the week (see Figure 1).

Habitual physical activity levels were estimated using a maximum of six valid days per student. According to prescribed accelerometer testing protocols, at least four valid days were required to estimate habitual physical activity levels per week (Trost, McIver, \& Pate, 2005). In addition, complete accelerometer data for both Saturday and Sunday were required to be included in the analyses because physical activity levels in adolescents differ between weekdays and both weekend days (Jago et al., 2005), a trend that was also found in our data (see the Results section).

Two measures of physical activity were used as independent variable: (1) total physical activity volume per week (Total PA), and (2) total moderate-to-vigorous physical activity per week (MVPA). Total PA was determined by the total number of accelerometer steps per week measured by the accelerometer, and MVPA was calculated by the total number of accelerometer steps per week with a cadence of $\geq 100$ steps/minute, which was based on the growing consensus that a cadence of $100 \mathrm{steps} / \mathrm{minute}$ represents a reasonable minimum level for moderate physical activity in adolescents and adults (Dall, McCrorie, Granat, \& Stansfield, 2013).

Academic Achievement. School grades (ranging from $1.0=$ very bad to $10.0=$ outstanding) were provided by the school at the end of the academic year. The mean scores of the school grades for Dutch (native language), mathematics, and English as a modern foreign language were used as measures of academic achievement, according to research of Sigfúsdóttir et al. (2007). In addition, the largest effects in academic achievement due to physical activity were expected in mathematics performance (Howie \& Pate, 2012), so the mean school grade for mathematics was analyzed separately as well.

Executive Functioning. The d 2 Test of Attention (Brickenkamp \& Zillmer, 1998) was used as measure of response inhibition (Budde, Voelcker-Rehage, PietrabykKendziorra, Ribeiro, \& Tidow, 2008), a key component of executive functioning (Alvarez \& Emory, 2006), and 


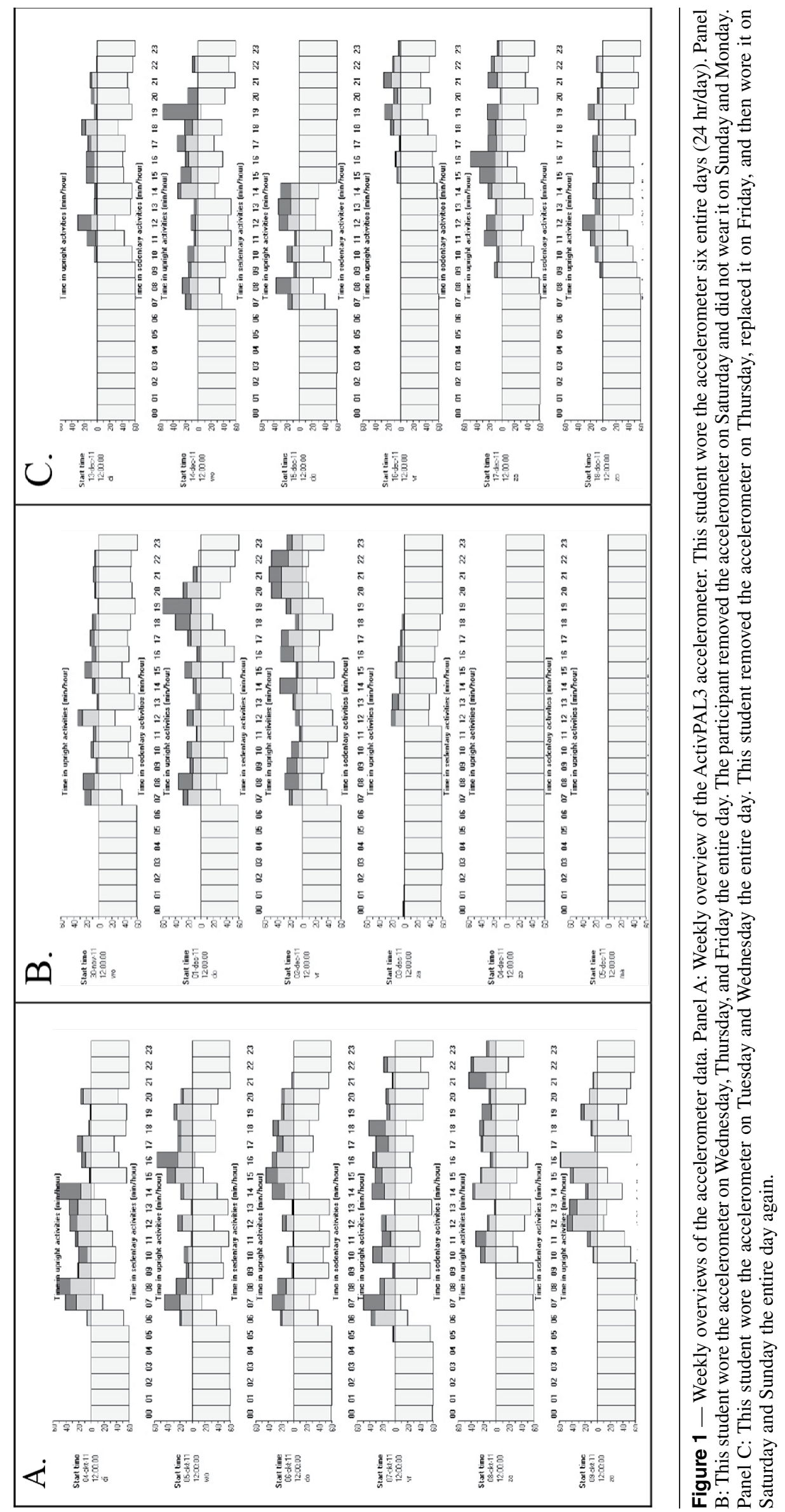


more broadly executive attention and concentration (Budde et al., 2008). The d2 Test of Attention is a widely used neuropsychological test and the construct validity has been well supported in European samples (Bates \& Lemay, 2004). It consists of 14 rows, each with 47 interspersed "p" and "d" characters. The characters had one to four dashes configured individually or in pairs above and/or below each letter. The target symbol was a letter $d$ with two dashes (hence "d2"), regardless of whether the dashes appeared both above the "d," both below the "d," or one above and one below the "d." The participant's task was to cross out as many target symbols as possible, moving from left to right, with a limit of 20 s/row. No pauses were allowed. An overall performance score was calculated by the total number of correctly crossed-out symbols minus total number incorrectly crossed-out symbols.

Covariates. Several demographic and behavioral variables associated with physical activity and academic achievement were used as covariates. Sex (coded as -0.5 $=$ boys, $0.5=$ girls), nationality (coded as $-0.5=$ native Dutch; i.e., both parents/guardians born in the Netherlands and $0.5=$ nonnative Dutch), academic year (coded as -0.5 $=$ Grade 7, $0.5=$ Grade 9), and school level (coded as -0.5 $=$ senior general secondary education [HAVO] and $0.5=$ university preparatory education [VWO]) were centered.

Socioeconomic status (SES) was measured by the highest educational level of the parents/guardians as reported by the parents or guardians themselves. If the parents/guardians had at most a secondary vocational education level, SES was coded as low-medium $=-0.5$; in all other cases, SES was coded as high $=0.5$ following the Dutch national classification (Dutch Ministry of Public Health, Welfare and Sport, 2011). In cases where the parents/guardians did not report their educational levels, SES was based on student report (44.9\%).

Weight in kilograms (rounded) and height in meters (two decimals) were measured in light clothing without shoes. The body mass index (BMI) was then calculated by dividing the weight by the height squared. Maximum oxygen consumption $\left(\mathrm{VO}_{2} \max \right)$ was used as indication of cardiovascular fitness and estimated by the 20-m shuttle run test (Leger, Mercier, Gadoury, \& Lambert, 1988). The test consisted of 1-min stages of continuous incremental pace running. Participants were required to run between two lines placed on the floor $20 \mathrm{~m}$ apart while keeping pace with audio signals. All measurements were carried out under standardized conditions on an indoor rubberfloored gymnasium. The initial speed was $8.5 \mathrm{kph}$, which increased by $0.5 \mathrm{kph}$ each successive minute, reaching $18.0 \mathrm{kph}$ at Minute 20. Participants were encouraged to continue running as long as possible throughout the course of the test. The test was finished when the participant failed to reach the end lines concurrent with the audio signals on two consecutive occasions. Otherwise, the test ended when the participant stopped because of fatigue. The last completed stage or half-stage at which the participant dropped out was scored. Using this score and the variables of sex, age, and $\mathrm{BMI}, \mathrm{VO}_{2} \max$ was estimated using the equation of Matsuzaka et al. (2004): $\mathrm{VO}_{2} \mathrm{max}=25.9-2.21$ $\times$ Sex $-0.449 \times$ Age $-0.831 \times$ BMI $+4.12 \times(8+0.5 \times$ 20 -m shuttle run test score). This equation was validated in children and adolescents and correlated strongly $(r=.80$, $p<.001$ ) with $\mathrm{VO}_{2}$ max measured directly on a treadmill.

The Pubertal Developmental Scale was used to determine the participants' phase of pubertal development (Petersen, Crockett, Richards, \& Boxer, 1988). The scale has good reliability (alpha coefficients of the items range from .63 to $.83, p<.001$ ) (Petersen et al., 1988) and high correlations (ranging from .61 to .67, $p<.001$ ) with physician ratings in adolescent girls (Brooks-Gunn, Warren, Rosso, \& Gargiulo, 1987). Participants were asked about growth, body hair and skin changes (all), changes to voice, growth of facial hair (males), breast development, and onset age of menstruation (females). The pubertal phase (ranging from $1=$ prepubertal to $4=$ postpubertal) was calculated by the average score of the answered questions.

The Center for Epidemiologic Studies Depression Scale (CES-D) was used to measure depressive symptoms experienced by participants (Radloff, 1977). Recent research has shown that the CES-D is an appropriate measurement instrument for depression in adolescents, with an internal consistency (Cronbach's alpha) ranging from .78 to .82 (Verhoeven, Sawyer, \& Spence, 2013). In this 20 -item self-report scale, students rated the frequency of 20 depressive symptoms over the previous week. A total severity score was calculated by summing all items, and the score ranged from 0 (not depressed) to 60 (a high amount of depressive symptoms).

The Rosenberg Self-Esteem Scale was used to measure global self-esteem (Rosenberg, 1979). Research in adolescents has revealed that the Rosenberg Self-Esteem Scale is a strong indicator of an adolescent's global self-esteem (Hagborg, 1993). The scale consists of 10 statements dealing with general feelings about the respondent's own self. The score is calculated by summing all items and ranges from 0 (minimum score of self-esteem) to 30 (maximum score of self-esteem).

Total light-intensity physical activity per week (LIPA) was used as covariate only in MVPA analyses; LIPA was calculated by determining the total number of accelerometer steps per week with a cadence of $<100$ steps/min: in other words, the Total PA minus the MVPA.

\section{Statistics}

Analyses were performed with the Statistical Package for the Social Sciences (SPSS) for Windows (version 19.0; SPSS, Inc., Chicago, IL, US). The level of significance was .05. Sex and academic year differences were analyzed by independent sample $t$ tests and Pearson's chi-square test for continuous and dichotomous variables, respectively. Pearson's correlation was used to investigate the correlations between both Total PA and MVPA and health outcomes BMI, cardiovascular fitness, self-esteem, and depressive symptoms. 
Associations between Total PA and academic achievement were analyzed by multiple linear regression analyses involving three steps, while controlling for covariates. Continuous variables and covariates were transformed into $z$-scores before they were entered in the multiple regression models. Associations between covariates and academic achievement were modeled (Step A). This step allowed us to control the results for possible confounding effects of the covariates. We considered controlling the results for MVPA as well; however, this action would have falsified the assumption of absence of multicollinearity, as the Pearson's correlation between Total PA and MVPA was large $(r=.837, P<.001)$. Then, Total PA was added to the model (Step B). This step allowed us to investigate the added explained variance of Total PA to the model. Finally, data were explored for potential interaction effects of sex and academic year on the associations between Total PA and academic achievement. Interaction terms were calculated between the $z$-score of the Total PA and the centered (i.e., -0.5 and +0.5 coded) scores of sex and academic year and then added to the model (Step C). In addition, simple slopes analyses were performed for significant interaction effects in model $\mathrm{C}$ to further investigate the nature of the statistical interactions. The same steps were conducted to analyze the associations between MVPA and academic achievement; however, to investigate whether MVPA was associated with academic achievement independently of LIPA, we added LIPA as a covariate to this model. This process did not falsify the assumption of absence of multicollinearity because the Pearson's correlation between LIPA and MVPA was small to medium $(r=.320, P<.001)$.

Furthermore, possible inverted U-shape associations between physical activity (both Total PA and MVPA) and academic achievement were analyzed by multiple linear regression analyses. In these analyses, a model with a centered score of Total PA or MVPA was compared with a model with a centered as well as a squared score. The difference in explained variance between these models was compared with determine if any inverted U-shape association existed.

Finally, whether the association between physical activity and academic achievement was mediated by executive functioning was investigated by multiple linear regression analysis using the method of Preacher and Hayes (2008). Using this method, the same variables and steps as described above were used to investigate the association between physical activity and executive functioning, and in turn between executive functioning and academic achievement. In addition, when these associations were found to be significant, we analyzed whether executive functioning mediated the association between physical activity and academic achievement using the indirect bootstrap analyses for mediation models of Preacher and Hayes (2008).

The p-p plots of the multiple regression analyses indicated a normal distribution of the errors and multicollinearity was no issue (Pearson's correlation between covariates $<.80$ ). The reported results of the multiple regression analyses excluded outliers ( $>3$ standard deviations).

\section{Results}

\section{Preliminary Results}

Total physical activity volume per day differed significantly between weekdays $(10,733 \pm 3,104$ accelerometer steps) and Saturday (9,675 $\pm 5,968$ accelerometer steps, $p=.001$, paired $t$ test), between weekdays and Sunday $(6,294 \pm 4,159$ accelerometer steps, $p<.001)$, and between Saturday and Sunday $(p<.001)$. Total moderateto-vigorous physical activity per day also differed significantly between weekdays $(4,474 \pm 2,145$ accelerometer steps) and Saturday $(3,250 \pm 3,326$ accelerometer steps, $p<.001$, paired $t$ test), between weekdays and Sunday $(1,570 \pm 2,277$ accelerometer steps, $p<.001)$, and between Saturday and Sunday $(p<.001)$.

\section{Characteristics of the Study Participants}

The descriptive statistics are shown in Table 1. Total PA was significantly higher in boys than in girls and in Grade 7 than in Grade 9. MVPA was also significantly higher in boys than in girls, while LIPA was significantly higher in Grade 7 than in Grade 9. Boys had significantly higher cardiovascular fitness and self-esteem than girls, while the pubertal phase and self-reported depressive symptoms were higher in girls than in boys. BMI and pubertal phase were significantly higher in Grade 9 than in Grade 7, while self-esteem was higher in Grade 7 than in Grade 9. Academic achievement and mathematics performance were significantly greater in girls than in boys and also in Grade 7 than in Grade 9. Executive functioning was significantly greater in girls than in boys and also in Grade 9 than in Grade 7.

\section{Associations Between Physical Activity and Health Outcomes}

Total PA was positively associated with cardiovascular fitness $(r=.313, p<.001)$ and self-esteem $(r=.158, p=$ $.012)$, and negatively associated with BMI $(r=-.184, p$ $=.003)$ and depressive symptoms $(r=-.158, p=.012)$. MVPA was positively associated with cardiovascular fitness $(r=.238, P<.001)$ and self-esteem $(r=.126$, $p=.048)$.

\section{Associations Between Total PA and Academic Achievement or Mathematics Performance}

Multiple linear regression analyses revealed that Total PA was overall not significantly associated with academic achievement and mathematics performance (Table 2, Step B). A significant interaction effect between Total PA and academic year on academic achievement was found (Table 2, Step C). Simple slopes analysis showed 
Table 1 Descriptive Statistics of the Study Sample

\begin{tabular}{|c|c|c|c|c|c|}
\hline & $\begin{array}{c}\text { All } \\
(n=255)\end{array}$ & $\begin{array}{c}\text { Boys } \\
\text { ( } n=116 ; 45.5 \%)\end{array}$ & $\begin{array}{c}\text { Girls } \\
(n=139)\end{array}$ & $\begin{array}{c}\text { Grade } 7 \\
\text { (n = 152; } 59.6 \%)\end{array}$ & $\begin{array}{l}\text { Grade } 9 \\
(n=103)\end{array}$ \\
\hline Age (years) & $13.02(1.08)$ & $12.91(1.04)$ & $13.10(1.10)$ & $12.21(0.46)^{\mathrm{b}}$ & $14.20(0.42)^{\mathrm{b}}$ \\
\hline \multicolumn{6}{|l|}{ Nationality } \\
\hline Native Dutch & $224(88.9 \%)$ & $105(91.3 \%)$ & $119(86.9 \%)$ & $133(88.7 \%)$ & $91(89.2 \%)$ \\
\hline Nonnative Dutch & 28 & 10 & 18 & 17 & 11 \\
\hline \multicolumn{6}{|l|}{ School level } \\
\hline Senior general secondary education & $84(32.9 \%)$ & $38(32.8 \%)$ & $46(33.1 \%)$ & $56(36.8 \%)$ & $28(27.2 \%)$ \\
\hline University preparatory education & 171 & 78 & 93 & 96 & 75 \\
\hline \multicolumn{6}{|l|}{ SES } \\
\hline Low-medium & $55(22.0 \%)$ & $21(18.6 \%)$ & $34(24.8 \%)$ & $35(23.6 \%)$ & $20(19.6 \%)$ \\
\hline High & 195 & 92 & 103 & 113 & 82 \\
\hline BMI & $18.82(2.75)$ & $18.81(2.83)$ & $18.82(2.69)$ & $18.06(2.76)^{\mathrm{b}}$ & $19.92(2.33)^{\mathrm{b}}$ \\
\hline Cardiovascular fitness & $50.59(4.92)$ & $54.30(5.19)^{\mathrm{a}}$ & $49.82(4.50)^{\mathrm{a}}$ & $51.71(5.57)$ & $52.05(4.90)$ \\
\hline Pubertal phase & $2.44(0.77)$ & $2.14(0.66)^{\mathrm{a}}$ & $2.70(0.77)^{\mathrm{a}}$ & $2.11(0.67)^{\mathrm{b}}$ & $2.94(0.63)^{\mathrm{b}}$ \\
\hline Depressive symptoms & $11.44(8.53)$ & $9.15(7.03)^{\mathrm{a}}$ & $13.27(9.18)^{\mathrm{a}}$ & $11.19(8.84)$ & $11.81(8.08)$ \\
\hline Self-esteem & $21.99(5.04)$ & $23.51(4.57)^{\mathrm{a}}$ & $20.78(5.09)^{\mathrm{a}}$ & $22.61(5.17)^{\mathrm{b}}$ & $21.12(4.74)^{\mathrm{b}}$ \\
\hline LIPA & $42,086(11,198)$ & $42,747(10,748)$ & $41,535(11,569)$ & $45,041(11,364)^{\mathrm{b}}$ & $37,727(9,428)^{\mathrm{b}}$ \\
\hline MVPA & $26,777(11,634)$ & $29,504(12,295)^{\mathrm{a}}$ & $24,501(10,568)^{\mathrm{a}}$ & $28,203(12,087)$ & $24,673(10,641)$ \\
\hline Total PA & $68,863(18,395)$ & $72,251(19,037)^{\mathrm{a}}$ & $66,036(17,409)^{\mathrm{a}}$ & $73,243(18,780)^{\mathrm{b}}$ & $62,400(15,801)^{\mathrm{b}}$ \\
\hline Percentage MVPA of total PA & $38.03 \%$ & $39.91 \%$ a & $36.45 \%$ a & $37.62 \%$ & $38.63 \%$ \\
\hline Total included valid days & $5.82(0.42)$ & $5.80(0.46)$ & $5.84(0.39)$ & $5.76(0.46)^{\mathrm{b}}$ & $5.91(0.35)^{\mathrm{b}}$ \\
\hline Academic achievement & $6.94(0.76)$ & $6.74(0.73)^{\mathrm{a}}$ & $7.10(0.75)^{\mathrm{a}}$ & $7.13(0.73)^{\mathrm{b}}$ & $6.65(0.71)^{b}$ \\
\hline Mathematics performance & $7.04(1.04)$ & $6.89(1.04)^{\mathrm{a}}$ & $7.16(1.04)^{\mathrm{a}}$ & $7.23(1.01)^{\mathrm{b}}$ & $6.75(1.03)^{\mathrm{b}}$ \\
\hline D2 Test of attention & $174.65(24.71)$ & $170.60(25.65)^{\mathrm{a}}$ & $178.05(23.44)^{\mathrm{a}}$ & $169.14(22.41)^{b}$ & $182.86(25.77)^{\mathrm{b}}$ \\
\hline
\end{tabular}

Note. SES = socioeconomic status, BMI = body mass index, LIPA = total light-intensity physical activity volume per week, MVPA = total moderate-to-vigorous physical activity volume per week, Total PA = total physical activity volume per week.

a Statistically significant difference between the sexes at $p<.05$.

${ }^{\mathrm{b}}$ Statistically significant difference between the school grades at $p<.05$.

a significantly negative association between Total PA and academic achievement in Grade $7(\beta=-.23, p=.007)$ and no significant association in Grade $9(\beta=.09, p=$ .393) (see Figure 2, left panel). Furthermore, a significant interaction effect between Total PA and academic year on mathematics performance was found (Table 2, Step C). Simple slopes analysis revealed a significantly positive association between Total PA and mathematics performance in Grade $9(\beta=.27, p=.018)$, but no significant association in Grade 7 ( $\beta=-.17, p=.057)$ (see Figure 2 , right panel).

Inverted U-shape analysis showed that the multiple regression model including centered Total PA as the independent variable explained $27.2 \%$ of the variance in academic achievement. The multiple regression model that included both centered Total PA and centered and squared Total PA as independent variables explained $27.4 \%$ of the variance in academic achievement. The difference in explained variance between these models was not significant $\left(\Delta R^{2}=.002, P=.501\right)$; therefore, no inverted U-shape association was found between Total PA and academic achievement.

\section{Associations Between MVPA and Academic Achievement or Mathematics Performance}

MVPA was overall not significantly associated with academic achievement and mathematics performance (Table 3, Step B). A significant interaction effect between MVPA and academic year on academic achievement was found (Table 3, Step C). Simple slopes analysis showed a significantly negative association between MVPA and academic achievement in Grade $7(\beta=-.22, p=.011)$ and no significant association in Grade $9(\beta=.15, p=.147)$ (see Figure 3, left panel). At the same time, a significant interaction effect between MVPA and academic year on mathematics performance was found (Table 3, Step C). Simple slopes analysis revealed a significantly negative association between MVPA and mathematics performance in Grade $7(\beta=-.23, p=.013)$, but a significantly positive association in Grade $9(\beta=.24, p=.035)$ (see Figure 3, right panel).

Inverted U-shape analyses showed that the multiple regression model including centered MVPA as the 

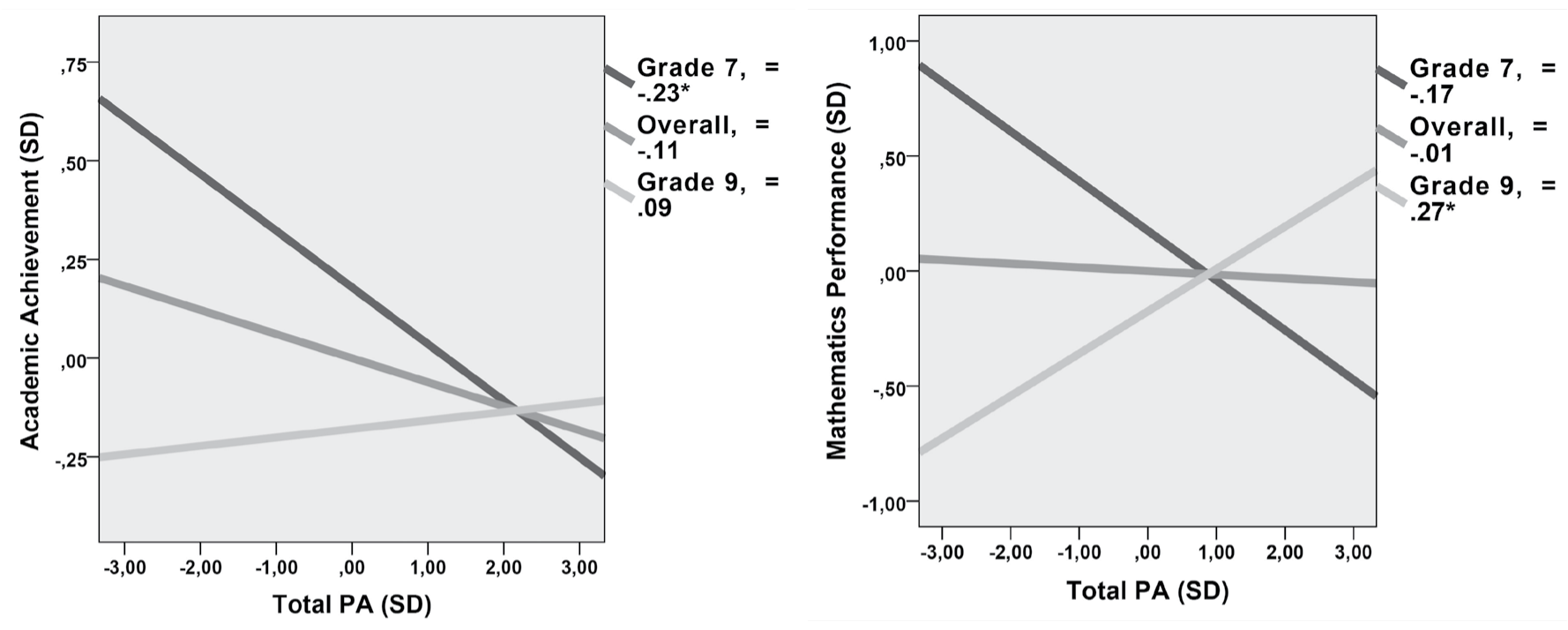

Figure 2 - Interactions between Total PA and academic year on academic achievement and mathematics performance. Left: Associations between Total PA and academic achievement. Right: Associations between Total PA and mathematics performance. Associations were analyzed overall by multiple linear regression analyses (see Tables 2 and 3, Step B) and separately in Grade 7 and Grade 9 by simple slopes analysis (see Results section). Total PA = total physical activity volume per week. $\beta=$ standardized regression coefficients. $* P<.05$.

Table 2 Multiple Linear Regression Analyses Using Total PA as Independent Variable

\begin{tabular}{|c|c|c|c|c|c|c|c|c|c|}
\hline & \multicolumn{3}{|c|}{$\begin{array}{c}\text { Academic } \\
\text { Achievement }\end{array}$} & \multicolumn{3}{|c|}{$\begin{array}{l}\text { Mathematics } \\
\text { Performance }\end{array}$} & \multicolumn{3}{|c|}{$\begin{array}{l}\text { d2 Test of } \\
\text { Attention }\end{array}$} \\
\hline & $\Delta \boldsymbol{R}^{2}$ & Adj. $R^{2}$ & $\beta$ & $\Delta \boldsymbol{R}^{2}$ & Adj. $R^{2}$ & $\beta$ & $\Delta \boldsymbol{R}^{2}$ & Adj. $R^{2}$ & $\beta$ \\
\hline Step A & $.26 *$ & .23 & & $.17 *$ & .13 & & $.12 *$ & .08 & \\
\hline Sex & & & $.30 *$ & & & $.25^{*}$ & & & .15 \\
\hline Nationality & & & $.17 *$ & & & $.14^{*}$ & & & .02 \\
\hline Academic year & & & $-.41 *$ & & & $-.22 *$ & & & $.21 *$ \\
\hline School level & & & $.17 *$ & & & $.19 *$ & & & .10 \\
\hline SES & & & .07 & & & .04 & & & .07 \\
\hline BMI & & & .05 & & & .01 & & & .02 \\
\hline Cardiovascular fitness & & & .08 & & & .10 & & & .07 \\
\hline Pubertal phase & & & .03 & & & -.06 & & & .09 \\
\hline Depressive symptoms & & & -.06 & & & -.05 & & & .09 \\
\hline Self-Esteem & & & .00 & & & .07 & & & .08 \\
\hline Step B & .01 & .24 & & .00 & .13 & & $.02 *$ & .09 & \\
\hline Total PA & & & -.11 & & & -.01 & & & $.15^{*}$ \\
\hline Step C & $.02 * *$ & .25 & & $.04 *$ & .16 & & .00 & .09 & \\
\hline Total PA $\times$ Sex & & & -.02 & & & .09 & & & .04 \\
\hline Total PA $\times$ Academic year & & & $.15^{*}$ & & & $.18 *$ & & & .04 \\
\hline
\end{tabular}

Note. Step A = model including covariates; Step B = model including Step A and independent variable Total PA; Step C = model including Step B and potential interaction effects. $\mathrm{SES}=$ socioeconomic status, $\mathrm{BMI}=$ body mass index, Total PA $=$ total physical activity volume per week. $\beta=$ standardized regression coefficients.

$* p<.05 . * * p=.053$. 

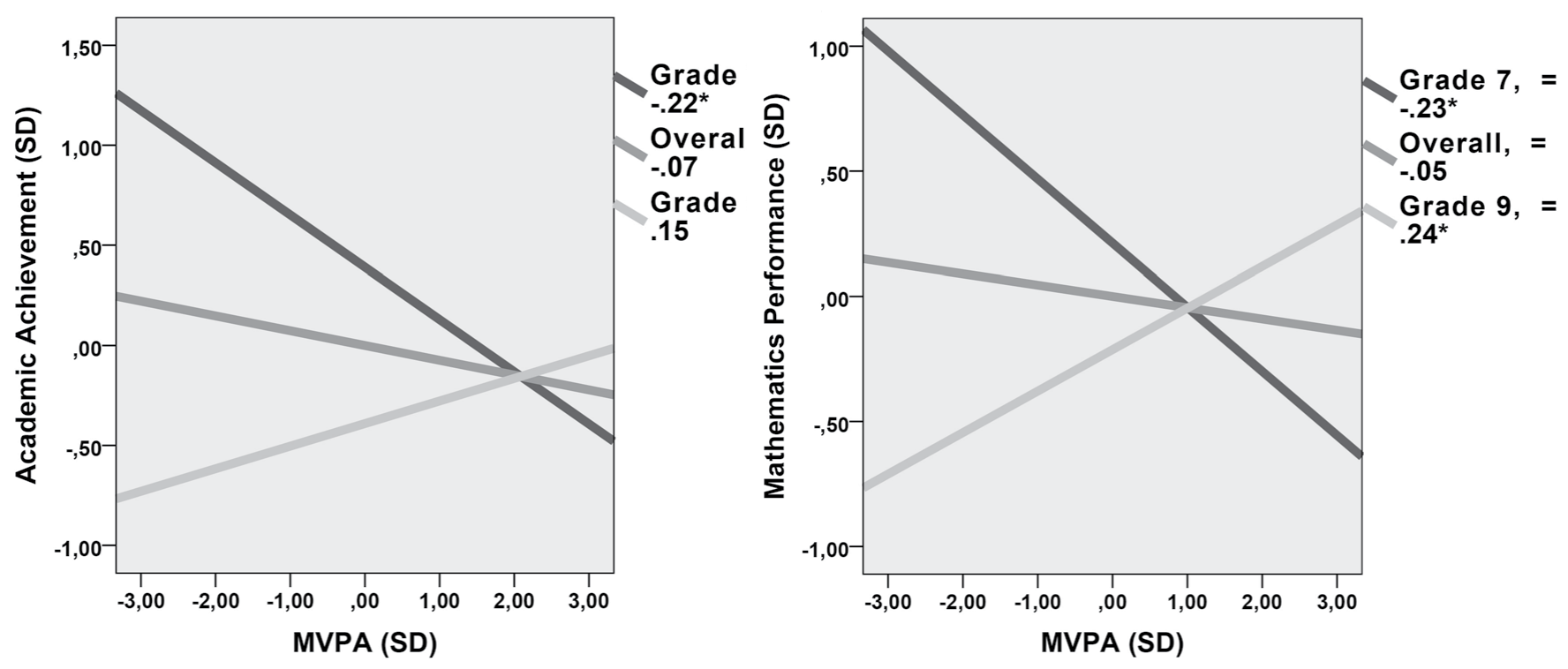

Figure 3 - Interactions between MVPA and academic year on academic achievement and mathematics performance. Left: Associations between MVPA and academic achievement. Right: Associations between MVPA and mathematics performance. Associations were analyzed overall by multiple linear regression analyses (see Tables 2 and 3, Step B) and separately in Grade 7 and Grade 9 by simple slopes analysis (see Results section). MVPA = total moderate-to-vigorous intensity physical activity volume per week. $\beta=$ standardized regression coefficients. $* P<.05$.

Table 3 Multiple Linear Regression Analyses Using MVPA as Independent Variable

\begin{tabular}{|c|c|c|c|c|c|c|c|c|c|}
\hline & \multicolumn{3}{|c|}{$\begin{array}{c}\text { Academic } \\
\text { Achievement }\end{array}$} & \multicolumn{3}{|c|}{$\begin{array}{l}\text { Mathematics } \\
\text { Performance }\end{array}$} & \multicolumn{3}{|c|}{$\begin{array}{l}\text { d2 Test of } \\
\text { Attention }\end{array}$} \\
\hline & $\Delta \boldsymbol{R}^{2}$ & Adj. $R^{2}$ & $\beta$ & $\Delta \boldsymbol{R}^{2}$ & Adj. $R^{2}$ & $\beta$ & $\Delta \boldsymbol{R}^{2}$ & Adj. $R^{2}$ & $\beta$ \\
\hline Step A & $.26^{*}$ & .22 & & $.17 *$ & .13 & & $.13^{*}$ & .08 & \\
\hline Sex & & & $.31 *$ & & & $.24^{*}$ & & & .13 \\
\hline Nationality & & & $.17 *$ & & & $.14 *$ & & & .02 \\
\hline Academic year & & & $-.38 *$ & & & $-.21 *$ & & & $.25 *$ \\
\hline School level & & & $.16^{*}$ & & & $.19^{*}$ & & & .10 \\
\hline SES & & & .06 & & & .04 & & & .07 \\
\hline BMI & & & .03 & & & .00 & & & -.02 \\
\hline Cardiovascular fitness & & & .06 & & & .09 & & & .03 \\
\hline Pubertal phase & & & -.02 & & & -.06 & & & .10 \\
\hline Depressive symptoms & & & -.05 & & & -.05 & & & .11 \\
\hline Self-Esteem & & & .03 & & & .07 & & & .09 \\
\hline LIPA & & & -.08 & & & .03 & & & .12 \\
\hline Step B & .00 & .22 & & .00 & .12 & & .01 & .09 & \\
\hline MVPA & & & -.07 & & & -.04 & & & .09 \\
\hline Step C & $.03^{*}$ & .24 & & $.05^{*}$ & .17 & & .01 & .09 & \\
\hline MVPA $\times$ Sex & & & .00 & & & .10 & & & .05 \\
\hline MVPA $\times$ Academic year & & & $.17 *$ & & & $.20^{*}$ & & & .05 \\
\hline
\end{tabular}

Note. Step A = model including covariates; Step B = model including Step A and independent variable MVPA; Step C = model including Step B and potential interaction effects. SES = socioeconomic status, BMI = body mass index, LIPA = total light-intensity physical activity volume per week, MVPA = total moderate-to-vigorous physical activity volume per week. $\beta=$ standardized regression coefficients.

${ }^{*} p<.05$. 
independent variable explained $25.9 \%$ of the variance in academic achievement. A multiple regression model including both centered MVPA and centered and squared MVPA as independent variables explained $27.3 \%$ of the variance in academic achievement. The difference in explained variance between these models was significant $\left(\Delta R^{2}=.014, p=.039\right)$; therefore, an inverted U-shape association was found between MVPA and academic achievement.

\section{Associations Between Both Total PA and MVPA and Executive Functioning}

Total PA was positively associated with performance on the $\mathrm{d} 2$ Test of Attention (Table 2, Step B). As a result, a basic requirement for mediation analyses was fulfilled for executive functioning (i.e., performance on the $\mathrm{d} 2$ Test of Attention) in the association between Total PA and academic achievement or mathematics performance. In addition, no significant interaction effects between Total PA and both sex and academic year on executive functioning were found (Table 2, Step C).

MVPA was not significantly associated with performance on the d2 Test of Attention (Table 2, Step B) and also no significant interaction effects were found (Table 2, Step C). Therefore, executive functioning did not mediate the associations between MVPA and academic achievement or mathematics performance.

\section{Associations Between Executive Functioning and Academic Achievement or Mathematics Performance}

Performance on the $\mathrm{d} 2$ Test of Attention was positively associated with academic achievement $(\beta=.14, p=.027)$ and mathematics performance $(\beta=.23, p<.001)$. As a result, a second requirement for mediation analyses was fulfilled for executive functioning (i.e., performance on the $\mathrm{d} 2$ Test of Attention) in the association between Total PA and academic achievement or mathematics performance. In addition, no significant interaction effects (sex and academic year) between performance on the $\mathrm{d} 2$ Test of Attention and academic achievement or mathematics performance were found.

\section{Mediating Role of Executive Functioning in the Association Between Total PA and Academic Achievement or Mathematics Performance}

Bootstrap analysis for mediation models showed a positive indirect effect of Total PA on academic achievement through executive functioning (effect $=.0357$; bootstrap confidence intervals between .0050 and .0849). In addition, also a positive indirect effect of Total PA on mathematics performance through executive functioning has been found (effect $=.0351$; bootstrap confidence intervals between .0064 and .0803).

\section{Discussion}

The main goal of the current study was to investigate the association between objectively measured physical activity and academic achievement in adolescents. The results indicated no significant overall dose-response association between Total PA or MVPA and academic achievement in our study sample of Dutch adolescents in Grades 7 and 9. However, in Grade 7 Total PA was negatively associated with academic achievement, while MVPA was negatively associated with both academic achievement and mathematics performance. In contrast, in Grade 9 both Total PA and MVPA were positively associated with mathematics performance. In addition, the overall association between MVPA and academic achievement followed an inverted U-shape curve. Finally, we found a positive association between Total PA and executive functioning, and an indirect positive association between Total PA and both academic achievement and mathematics performance by executive functioning. Our research expands previous studies of Kwak et al. (2009), Syväoja et al. (2013), and Booth et al. (2014) by using four complete days ( $24 \mathrm{hr} /$ day) with accelerometer data, including both weekend days, to calculate habitual physical activity levels. In addition, we investigated whether the association between physical activity and academic achievement was mediated by executive functioning.

\section{Association Between Physical Activity and Academic Achievement}

We hypothesized a positive dose-response association between physical activity and academic achievement in adolescents. Our main result, that there was no significant association between physical activity and academic achievement overall, is in contrast with this hypothesis. We have three explanations for this.

First, both Total PA and MVPA were negatively associated with academic achievement in Grade 7, which is in line with the findings of Tremblay et al. (2000). In contrast, both Total PA and MVPA were positively associated with mathematics performance in Grade 9, which is in agreement with Kwak et al. (2009). This discrepancy between Grade 7 and Grade 9 might be explained by physically active students who spent time on physical activities at the expense of time devoted to homework (Syvaoja et al., 2013). Indeed, additional analyses of our data showed that both MVPA and Total PA were negatively correlated with self-reported time devoted to homework in Grade 7 but not in Grade 9. However, these results have to be interpreted with caution because it was unclear whether some students reported the total time devoted to homework per week or per day, which kept us from including this variable in the multiple regression analyses. In conclusion, we found possibly no significant overall dose-response association between physical activity and academic achievement because this association was moderated by academic year. 
Second, it might be that physical activity, up to some optimal level, is positively associated with academic achievement, while too much time spent on physical activity might detract from academic pursuits, such as time devoted to homework, resulting in a poorer academic achievement (Tremblay et al., 2000). Indeed, we found an inverted U-shape association between MVPA and academic achievement, which is in line with previous work of Syväoja et al. (2013). Furthermore, additional analysis of our data showed that MVPA was overall negatively correlated with time devoted to homework, while time devoted to homework was positively correlated with academic achievement, although not statistically significant. In addition, students in the lowest quartile of MVPA devoted 136 min per week to homework and students in the highest quartile of MVPA, $110 \mathrm{~min}$. However, this difference was again not statistically significant. In conclusion, it might be possible that MVPA is overall positively associated with academic achievement provided that time spent in MVPA, for example during sport activities, does not detract from time devoted to homework. However, because of the methodological limitations of the current study, this conclusion has to be taken with caution.

Finally, physical activity could have specific benefits in the academic domain associated with executive functioning. For example, the most beneficial effects of physical activity has been found on mathematics performance (Howie \& Pate, 2012), which is positively correlated with several components of executive functioning in youth (Bull \& Scerif, 2001). We found in Grade 9 that both Total PA and MVPA were positively associated with mathematics performance, but not with academic achievement (i.e., the mean of the school grades Dutch, English, and mathematics). These results might be explained by the executive function hypothesis: the largest improvements in cognition due to physical activity will be on executive functions (Davis et al., 2007), which are correlated with mathematics performance (Bull \& Scerif, 2001). In conclusion, we found that the association between physical activity and academic achievement might be impacted by school grade.

\section{Mediating Role of Executive Functioning in the Association Between Physical Activity and Academic Achievement}

We found a positive association between Total PA and executive functioning, while executive functioning in turn was positively associated with academic achievement and mathematics performance. As a result, it might be concluded that executive functioning mediated the associations between Total PA and both academic achievement and mathematics performance. As we found no overall association between Total PA and academic achievement or mathematics performance, the mediating role of executive functioning in the association between Total PA and academic achievement might be offset by other factors such as time devoted to homework as described above. In addition, an interaction between physical activity and academic year on executive functioning might explain the moderating role of academic year in the association between physical activity and academic achievement. We explored interaction effects between both Total PA and MVPA and academic year on executive functioning; however, we found no significant results (Tables 2 and 3, Step C).

In addition, Best, Miller, and Naglieri (2011) found that the correlation between executive functioning and academic achievement varied across ages. Therefore, an interaction between executive functioning and academic year on academic achievement or mathematics performance might explain the moderating role of academic year in the association between physical activity and academic achievement. However, additional analyses of our data showed no significant interaction effects between executive functioning and academic year on academic achievement or mathematics performance. Taken together, executive functioning did not explain the interaction effect between physical activity and academic year on academic achievement in our study sample of Dutch adolescents.

\section{Strengths}

The major strength of this study is that physical activity was measured objectively using the ActivPAL3 accelerometer, which has been found to be a reliable instrument to investigate physical activity in adolescents (Dowd, Harrington, \& Donnelly, 2012) and adults (Dahlgren, Carlsson, Moorhead, Hager-Ross, \& McDonough, 2010). In addition, because this accelerometer was placed on the thigh, it was capable of measuring nonambulant activities, such as cycling (Dahlgren et al., 2010), a common activity in Dutch adolescents (Chinapaw et al., 2009). Second, academic achievement and executive functioning were measured objectively. Finally, we controlled for several potential confounders, such as cardiovascular fitness and self-esteem, which were significantly correlated with Total PA in line with the literature (Biddle \& Asare, 2011; Santos et al., 2013).

\section{Limitations}

Our study had some limitations. First, its cross-sectional design made it impossible to determine causal relations. Second, results cannot be generalized to the entire Dutch adolescent population because only one secondary school was used. On the other hand, as schools often differ in grading and teaching policies, the choice for one secondary school increased the homogeneity of the variables regarding academic achievement. Third, a selection bias might have been present in this study because girls or obese adolescents were possibly less inclined to participate in the study compared with boys or slender adolescents, respectively. Nevertheless, the study sample was equally distributed by sex and the mean BMI was similar to the overall Dutch adolescent population (Snoek, van Strien, Janssens, \& Engels, 2007). 


\section{Conclusions}

The main results of this study showed no significant doseresponse association between physical activity and academic achievement in adolescents overall; however, this association might be impacted by academic year, physical activity volume and intensity, and school grade. To get more insight into the complex association between physical activity and academic achievement in adolescents, we recommend that future studies account for differences in physical activity levels between weekdays and weekend days and also take executive functioning and time devoted to homework into account. Finally, we found several positive associations between physical activity and both physical and mental health outcomes, including executing functioning, and an indirect positive association between physical activity and academic achievement by executive functioning. Therefore, despite the fact that we found no overall dose-response association between physical activity and academic achievement, we recommend schools to stimulate physical activity in adolescents.

\section{Acknowledgments}

This research was supported by the NIHC (Nationaal Initiatief Hersenen \& Cognitie [National Initiative Brain \& Cognition]) funded by FES (Fonds Economische Structuurversterking [Fund Economic Structure Reinforcement]).

\section{References}

Alvarez, J.A., \& Emory, E. (2006). Executive function and the frontal lobes: A meta-analytic review. Neuropsychology Review, 16, 17-42. PubMed doi:10.1007/s11065-0069002-x

Bassett, D.R., Jr., Cureton, A.L., \& Ainsworth, B.E. (2000). Measurement of daily walking distance-questionnaire versus pedometer. Medicine and Science in Sports and Exercise, 32, 1018-1023. doi:10.1097/00005768200005000-00021

Bates, M.E., \& Lemay, E.P., Jr. (2004). The d2 Test of attention: construct validity and extensions in scoring techniques. Journal of the International Neuropsychological Society, 10, 392-400. PubMed doi:10.1017/S135561770410307X

Best, J.R., Miller, P.H., \& Naglieri, J.A. (2011). Relations between Executive Function and Academic Achievement from Ages 5 to 17 in a Large, Representative National Sample. Learning and Individual Differences, 21, 327336. PubMed doi:10.1016/j.lindif.2011.01.007

Biddle, S.J., \& Asare, M. (2011). Physical activity and mental health in children and adolescents: A review of reviews. British Journal of Sports Medicine, 45, 886-895. PubMed doi:10.1136/bjsports-2011-090185

Booth, J.N., Leary, S.D., Joinson, C., Ness, A.R., Tomporowski, P.D., Boyle, J.M., \& Reilly, J.J. (2014). Associations between objectively measured physical activity and academic attainment in adolescents from a UK cohort. British Journal of Sports Medicine, 48, 265-270. PubMed doi:10.1136/bjsports-2013-092334
Booth, J.N., Tomporowski, P.D., Boyle, J.M., Ness, A.R., Joinson, C., Leary, S.D., \& Reilly, J.J. (2013). Associations between executive attention and objectively measured physical activity in adolescence: Findings from ALSPAC, a UK cohort. Mental Health and Physical Activity, 6, 212-219. doi:10.1016/j.mhpa.2013.09.002

Brickenkamp, R., \& Zillmer, E. (1998). The d2 Test of Attention. Seattle, Washington: Hogrefe \& Huber Publishers.

Brooks-Gunn, J., Warren, M.P., Rosso, J., \& Gargiulo, J. (1987). Validity of self-report measures of girls' pubertal status. Child Development, 58, 829-841. PubMed doi:10.2307/1130220

Budde, H., Voelcker-Rehage, C., Pietrabyk-Kendziorra, S., Ribeiro, P., \& Tidow, G. (2008). Acute coordinative exercise improves attentional performance in adolescents. Neuroscience Letters, 441, 219-223. PubMed doi:10.1016/j.neulet.2008.06.024

Bull, R., \& Scerif, G. (2001). Executive functioning as a predictor of children's mathematics ability: inhibition, switching, and working memory. Developmental Neuropsychology, 19, 273-293. PubMed doi:10.1207/S15326942DN1903_3

Castelli, D.M., Hillman, C.H., Buck, S.M., \& Erwin, H.E. (2007). Physical fitness and academic achievement in third- and fifth-grade students. Journal of Sport \& Exercise Psychology, 29, 239-252. PubMed

Chillón, P., Ortega, F.B., Ruiz, J.R., De Bourdeaudhuij, I., Martinez-Gomez, D., Vicente-Rodriguez, G., . . . Sjostrom, M. (2011). Active commuting and physical activity in adolescents from Europe: results from the HELENA study. Pediatric Exercise Science, 23, 207-217. PubMed

Chinapaw, M.J., Slootmaker, S.M., Schuit, A.J., van Zuidam, M., \& van Mechelen, W. (2009). Reliability and validity of the Activity Questionnaire for Adults and Adolescents (AQuAA). BMC Medical Research Methodology, 9, 58-65. PubMed doi:10.1186/1471-2288-9-58

Coe, D.P., Pivarnik, J.M., Womack, C.J., Reeves, M.J., \& Malina, R.M. (2006). Effect of physical education and activity levels on academic achievement in children. Medicine and Science in Sports and Exercise, 38, 1515-1519. PubMed doi:10.1249/01.mss.0000227537.13175.1b

Crone, E.A., \& Dahl, R.E. (2012). Understanding adolescence as a period of social-affective engagement and goal flexibility. Nature Reviews. Neuroscience, 13, 636-650. PubMed doi:10.1038/nrn3313

Dahlgren, G., Carlsson, D., Moorhead, A., Hager-Ross, C., \& McDonough, S.M. (2010). Test-retest reliability of step counts with the ActivPAL (TM) device in common daily activities. Gait \& Posture, 32, 386-390. PubMed doi:10.1016/j.gaitpost.2010.06.022

Daley, A.J., \& Ryan, J. (2000). Academic performance and participation in physical activity by secondary school adolescents. Perceptual and Motor Skills, 91, 531-534. PubMed doi:10.2466/pms.2000.91.2.531

Dall, P.M., McCrorie, P.R., Granat, M.H., \& Stansfield, B.W. (2013). Step Accumulation per Minute Epoch Is Not the Same as Cadence for Free-Living Adults. Medicine and Science in Sports and Exercise, 45, 1995-2001. PubMed doi:10.1249/MSS.0b013e3182955780 
Davis, C.L., Tomporowski, P.D., Boyle, C.A., Waller, J.L., Miller, P.H., Naglieri, J.A., \& Gregoski, M. (2007). Effects of aerobic exercise on overweight children's cognitive functioning: a randomized controlled trial. Research Quarterly for Exercise and Sport, 78, 510-519 doi:10.10 80/02701367.2007.10599450. PubMed

Dowd, K.P., Harrington, D.M., \& Donnelly, A.E. (2012). Criterion and concurrent validity of the activPAL professional physical activity monitor in adolescent females. PLoS ONE, 7:e47633. PubMed doi:10.1371/journal. pone. 0047633

Dutch Ministry of Public Health. Welfare and Sport. (2011). Nationale Atlas Volksgezondheid [National Atlas Public Health]. Sociaaleconomische status Nederlandse beroepsbevolking [Socioeconomic status Dutch workforce]. Available from: http://www.zorgatlas.nl/beinvloedendefactoren/sociale-omgeving/ses. Accessed April 10, 2013.

Fedewa, A.L., \& Ahn, S. (2011). The effects of physical activity and physical fitness on children's achievement and cognitive outcomes: a meta-analysis. Research Quarterly for Exercise and Sport, 82, 521-535. PubMed doi:10.10 80/02701367.2011.10599785

Fox, C.K., Barr-Anderson, D., Neumark-Sztainer, D., \& Wall, M. (2010). Physical activity and sports team participation: associations with academic outcomes in middle school and high school students. The Journal of School Health, 80, 31-37. PubMed doi:10.1111/j.1746-1561.2009.00454.x

Guiney, H., \& Machado, L. (2013). Benefits of regular aerobic exercise for executive functioning in healthy populations. Psychonomic Bulletin \& Review, 20, 73-86. PubMed doi:10.3758/s13423-012-0345-4

Hagborg, W.J. (1993). The Rosenberg Self-Esteem scale and Harter's Self-Perception profile for adolescents: A concurrent validity study. Psychology in the Schools, 30, 132136. doi:10.1002/1520-6807(199304)30:2<132::AIDPITS2310300205>3.0.CO;2-Z

Howie, E.K., \& Pate, R.R. (2012). Physical activity and academic achievement in children: A historical perspective. Journal of Sport and Health Science, 1, 160-169. doi:10.1016/j.jshs.2012.09.003

Ickovics, J.R., Carroll-Scott, A., Peters, S.M., Schwartz, M., Gilstad-Hayden, K., \& McCaslin, C. (2014). Health and academic achievement: cumulative effects of health assets on standardized test scores among urban youth in the United States. The Journal of School Health, 84, 40-48. PubMed doi:10.1111/josh.12117

Jago, R., Anderson, C.B., Baranowski, T., \& Watson, K. (2005). Adolescent patterns of physical activity differences by gender, day, and time of day. American Journal of Preventive Medicine, 28, 447-452. PubMed doi:10.1016/j. amepre.2005.02.007

Kwak, L., Kremers, S.P., Bergman, P., Ruiz, J.R., Rizzo, N.S., \& Sjostrom, M. (2009). Associations between physical activity, fitness, and academic achievement. The Journal of Pediatrics, 155, 914-918. PubMed doi:10.1016/j. jpeds.2009.06.019

Léger, L.A., Mercier, D., Gadoury, C., \& Lambert, J. (1988). The multistage 20 metre shuttle run test for aerobic fit- ness. Journal of Sports Sciences, 6, 93-101. PubMed doi:10.1080/02640418808729800

Matsuzaka, A., Takahashi, Y., Yamasoe, M., Kumakura, M., Ikeda, A., \& Wilk, B. (2004). Validity of the Multistage 20-M Shuttle-Run Test for Japanese Children, Adolescents, and Adults. Pediatric Exercise Science, 16, 113-125.

McCrorie, P.R., Duncan, E., Granat, M.H., \& Stansfield, B.W. (2012). The prevalence of upright non-stepping time in comparison to stepping time in 11-13 year old school children across seasons. Physiological Measurement, 33, 1901-1912. PubMed doi:10.1088/0967-3334/33/11/1901

Petersen, A.C., Crockett, L., Richards, M., \& Boxer, A. (1988). A self-report measure of pubertal status: Reliability, validity, and initial norms. Journal of Youth and Adolescence, 17, 117-132. PubMed doi:10.1007/BF01537962

Preacher, K.J., \& Hayes, A.F. (2008). Asymptotic and resampling strategies for assessing and comparing indirect effects in multiple mediator models. Behavior Research Methods, 40, 879-891. PubMed doi:10.3758/BRM.40.3.879

Radloff, L.S. (1977). The CES-D Scale: A self-report depression scale for research in the general population. Applied Psychological Measurement, 1, 385-401. doi:10.1177/014662167700100306

Rosenberg, M. (1979). Conceiving the self. New York: Basic Books.

Santos, R., Mota, J., Okely, A.D., Pratt, M., Moreira, C., Coelho, E.S.M.J., . . S Sardinha, L.B. (2013). The independent associations of sedentary behaviour and physical activity on cardiorespiratory fitness. British Journal of Sports Medicine, doi:10.1136/bjsports-2012-091610. PubMed

Sigfúsdóttir, I.D., Kristjánsson, A.L., \& Allegrante, J.P. (2007). Health behaviour and academic achievement in Icelandic school children. Health Education Research, 22, 70-80 10.1093/her/cyl044. PubMed doi:10.1093/her/cyl044

Slootmaker, S.M., Schuit, A.J., Chinapaw, M.J., Seidell, J.C., \& van Mechelen, W. (2009). Disagreement in physical activity assessed by accelerometer and self-report in subgroups of age, gender, education and weight status. The International Journal of Behavioral Nutrition and Physical Activity, 6:17 10.1186/1479-5868-6-17. PubMed doi:10.1186/1479-5868-6-17

Snoek, H.M., van Strien, T., Janssens, J.M., \& Engels, R.C. (2007). Emotional, external, restrained eating and overweight in Dutch adolescents. Scandinavian Journal of Psychology, 48, 23-32. PubMed doi:10.1111/j.14679450.2006.00568.x

So, W.-Y. (2012). Association between physical activity and academic performance in Korean adolescent students. BMC Public Health, 12:258. PubMed doi:10.1186/14712458-12-258

Steinberg, L. (2005). Cognitive and affective development in adolescence. Trends in Cognitive Sciences, 9, 69-74. PubMed doi:10.1016/j.tics.2004.12.005

Syväoja, H.J., Kantomaa, M.T., Ahonen, T., Hakonen, H., Kankaanpaa, A., \& Tammelin, T.H. (2013). Physical Activity, Sedentary Behavior, and Academic Performance in Finnish Children. Medicine and Science in Sports and Exercise, 45, 2098-2104. PubMed doi:10.1249/ MSS.0b013e318296d7b8 
Thomas, A.G., Dennis, A., Bandettini, P.A., \& Johansen-Berg, H. (2012). The effects of aerobic activity on brain structure. Frontiers in Psychology, 3:86. PubMed doi:10.3389/ fpsyg.2012.00086

Tremblay, M.S., Inman, J.W., \& Willms, J.D. (2000). The Relationship Between Physical Activity, Self-esteem, and Academic Achievement in 12-year-Old Children. Pediatric Exercise Science, 12, 312-323.

Trost, S.G., McIver, K.L., \& Pate, R.R. (2005). Conducting accelerometer-based activity assessments in fieldbased research. Medicine and Science in Sports and Exercise, 37, S531-S543. PubMed doi:10.1249/01. mss.0000185657.86065.98
Verhoeven, M., Sawyer, M.G., \& Spence, S.H. (2013). The factorial invariance of the CES-D during adolescence: are symptom profiles for depression stable across gender and time? Journal of Adolescence, 36, 181-190. PubMed doi:10.1016/j.adolescence.2012.10.007

Wigfield, A., Eccles, J.S., Iver, D.M., Reuman, D.A., \& Midgley, C. (1991). Transitions During Early Adolescence: Changes in Children's Domain-Specific-Perceptions and General Self-esteem Across the Transition to Junior High School. Developmental Psychology, 27, 552-565. doi:10.1037/0012-1649.27.4.552

Manuscript submitted: January 21, 2014

Revision accepted: August 2, 2014 